\title{
La utopía del desarrollo. Aportes para pensar alternativas viables
}

\section{The delevopment utopia. Contributions to think viable alternatives}

ARTÍCULO

\section{Juan Carlos Travela}

Centro Redes, Universidad Nacional de Quilmes, Argentina. Correo electrónico: juancarlostravela@hotmail.com

\begin{abstract}
Resumen
Las teorías del desarrollo, al menos las más difundidas de occidente, analizan y debaten arduamente los diferentes caminos para alcanzar el desarrollo, pero no con el mismo ímpetu la concepción del mismo. Desde propuestas muchas veces antagónicas, se debate el rol de las instituciones, la libre movilidad de los factores de producción, las capacidades tecnológicas, las relaciones con el mercado mundial, entre otros elementos importantes para un proceso de desarrollo. Sin embargo, el deterioro ambiental del planeta, que se manifiesta en múltiples dimensiones, ha llevado a la sostenibilidad a ser un elemento central para nuevas discusiones.

La comunidad internacional ha intentado abordarla en las últimas décadas sin éxito. Desde la óptica de este trabajo, esto se debe a la persistente pretensión de no abandonar la concepción original del desarrollo y pretender apaciguar sus externalidades mediante la ampliación del concepto.

Por este motivo, este trabajo se propone analizar los principales problemas de la concepción hegemónica del desarrollo, y avanzar en la construcción de posibles alternativas para la sociedad.

Para este objetivo, se presenta un estudio preliminar de la experiencia de las cooperativas de vivienda inscriptas en el Programa de Autogestión de la Vivienda de la Ciudad de Buenos Aires, en el que se intenta constatar si el cooperativismo puede ser una forma de organizar el trabajo positivo para promover el cambio de paradigma necesario para pensar en el desarrollo de forma verdaderamente sostenible.

Palabras Clave: Desarrollo Económico; Crisis Ambiental; Cooperativismo.

\section{Abstract}

The development theories, at least the most widespread in the West, analyze and debate arduously the different ways to achieve development, but not with the same impetus the conception of it. From proposals often antagonistic, the role of institutions, the free mobility of production factors, technological capabilities, relations with the world market, among other important elements for a development process are debated. However, the environmental deterioration of the planet, which manifests itself in multiple dimensions, has led to sustainability to be a central element for new discussions.
\end{abstract}


The international community has tried to address it in recent decades without success. From the point of view of this work, this is due to the persistent pretension not to abandon the original conception of development and to try to appease its externalities by broadening the concept. For this reason, this work aims to analyze the main problems of the hegemonic conception of development, and advance in the construction of possible alternatives for society.

For this purpose, a preliminary study about the experience of housing cooperatives registered in the Housing Self-Management Program of the City of Buenos Aires is presented, in order to verify if cooperativism can be a way of organizing work positive to promote the paradigm shift necessary to think about development in a truly sustainable way.

Keywords: Economic Development; Environmental crisis; Cooperativism.

\section{¿Por qué repensar el desarrollo?}

El Desarrollo es el gran objetivo de los países del Sur, y al menos desde la segunda mitad del siglo $\mathrm{XX}$, las discusiones y teorías respecto a las formas de alcanzarlo han ido paulatinamente ganando terreno, ya sea en la academia como así también en los organismos internacionales.

Como concepto, está fuertemente vinculado a la idea de modernidad, meta sociopolítica que debe buscar toda sociedad, basada de forma implícita, en los principios y valores de las sociedades europeas y norteamericana (Dos Santos, 2002). Así, la teoría del desarrollo se inicia con una concepción del mismo que lo entiende como

[...] la adopción de normas de comportamiento, actitudes y valores identificados con la racionalidad económica moderna, caracterizada por la búsqueda de la máxima productividad, la generación de ahorro y la creación de inversiones que llevasen a la acumulación permanente de los individuos y, en consecuencia, de cada sociedad nacional (Ibid, 2002. p. 2).

De esta manera, las ideas hegemónicas existentes respecto al desarrollo lo consideran una categoría económica que refiere al grado de avance de la estructura productiva (Vernengo, 2006). En este sentido, la acumulación de capital permite, a través de la inversión en tecnología, sostener, reproducir y ampliar los diferenciales de productividad, que es lo que termina por establecer la inserción de un país en la economía mundial, carácter fundamental que permite categorizar a un país como desarrollado o subdesarrollado.

Sin embargo, si bien se verifica que las ideas respecto al desarrollo se han ido ampliando con el correr de los años, introduciendo dimensiones sociales y ambientales, nunca han abandonado o cuestionado la concepción inicial y principal de este concepto: la acumulación de riqueza y capital.

Las recetas respecto a los caminos que debe seguir una nación para alcanzar el desarrollo son variadas según la tradición teórica que se analice. Así, se puede enfatizar en la 
acumulación de capital, el rol de Estado, la inversión extranjera directa, la innovación, las políticas en ciencia y tecnología, la dependencia (o no) respecto al mercado mundial, los términos de intercambio, la formas de utilización de los excedentes económicos, la flexibilidad de las instituciones, el libre acceso a los mercados y la movilidad de capital, entre otros elementos que agotan las bibliotecas económicas.

Estas diversas corrientes, en muchos casos antagónicas, coinciden en su idea respecto a qué implica el desarrollo y, como afirma Alvater (2011), ninguna cuestiona la creencia en el crecimiento económico como dimensión principal y condición necesaria para pensar en el desarrollo.

Esto afirma lo planteado por Lang (2011) respecto a lo sucedido en el siglo XX, donde tanto el modelo capitalista como la gran propuesta alternativa se asentaron en el desarrollo. Los gobiernos del socialismo real en Europa del Este y la mayoría de los actores de las izquierdas latinoamericanas se enfocaron en la crítica al imperialismo y al capitalismo como tal pero aceptaron tácitamente el concepto de desarrollo. No lo analizaron como uno de los dispositivos claves para afianzar y expandir el capitalismo y su lógica de producir colonias, que ata el bienestar solamente a la capacidad de consumo de la población.

Cabe preguntarnos entonces si hay espacio ambiental o bienes ecológicos suficientes para que algunos cientos de millones de personas se incorporen a lo que implica esta concepción del desarrollo (Riechman, 2006), o si continuamos los esfuerzos sabiendo que esta meta es excluyente, y que no puede ser para toda la humanidad en su conjunto.

En este sentido, como afirma León Olive (2003), hay buenas razones para preocuparse por las consecuencias del desarrollo y de las aplicaciones de la ciencia y la tecnología en el siglo XXI. Si tomamos en cuenta, como sostiene Ernest García (2006) que hacia la primera década de este siglo la huella ecológica mundial ya superaba en más de un $20 \%$ el nivel sostenible, la afirmación de la CEPAL (2016) y otros autores como Acosta y Brand (2017) resulta convincente: El capitalismo vive una crisis generalizada, multifacética e interrelacionada que ha llevado a la humanidad a un punto de no retorno, donde el impacto ambiental del estilo de desarrollo dominante ha puesto en peligro su supervivencia y la de otras especies.

De esta manera, Gudynas (2015) sostiene que al profundizar el examen de los problemas ambientales, siempre, explícitamente o no, está en juego la valoración que se tiene sobre el entorno. Así, la cultura occidental se caracteriza por estar centrada en el ser humano. A partir de considerarlo único por sus capacidades cognoscitivas, lo sitúa por encima del resto de los seres vivos del planeta, otorgándole otro valor diferencial, convirtiéndolo en único sujeto de derecho. De esta concepción del mundo, conocida como antropocentrismo, se desprende que la biodiversidad debe ser cuidada en función de las necesidades y deseos de los seres 
humanos. La naturaleza como categoría plural es desarticulada y es concebida como un conjunto de elementos vivos o no, tenedores o no de una utilidad extrínseca. Este sesgo utilitarista es un elemento central para entender cómo la apropiación de la naturaleza no se discute entre las diferentes corrientes políticas que han gobernado en las últimas décadas en América Latina, siendo el extractivismo uno de los elementos centrales de esta situación. De esta forma, en la pretensión de control, manipulación y su ética utilitarista está la base de la crisis ambiental.

Sin embargo, al calor de la disputa de sentidos necesaria para hacer frente a esta problemática, se han amplificado voces, algunas preexistentes a la occidentalización de nuestro subcontinente, que sostienen que el conjunto de especies y ecosistemas revisten valor en sí mismos, es decir, que poseen valor de forma intrínseca.

De esta manera, se defiende la independencia respecto al ser humano del valor que tiene cada elemento natural. Bajo esta concepción no es el hombre quien otorga valor a la naturaleza sino es la capacidad de cada elemento, en virtud de sus atributos, de proseguir con sus procesos ecológicos y alcanzar su bienestar lo que le permite poseer valor, el cual le es inherente (Gudynas, 2015).

Estas posturas, a su vez, se oponen a la idea desarticulada de la Naturaleza, sosteniendo que cada ser vivo es parte de un todo, lo que se conoce como principio de la unidad en la diversidad, rompiendo con la falsa dicotomía hombre-naturaleza dominante bajo la mirada antropocentrista. De esta manera, incluyendo a las sociedades humanas dentro de la naturaleza, la idea de "desarrollarnos" a costa de la depredación del ambiente se vuelve un absurdo, ya que el desarrollo necesariamente implica una progresión en las condiciones de la vida, y no una amenaza para la misma.

Sin embargo, en nuestra región el estilo de desarrollo dominante se basa en una estructura productiva cuya competitividad depende de la abundancia y la explotación de los recursos naturales (CEPAL, 2016). Esto se ha profundizado en gran parte del siglo XX y el siglo XXI, ya que como sostiene Hirch (1999), durante el posfordismo los Estados avanzaron en todo tipo de flexibilizaciones, desregulaciones y minimalización de los estándares ecológicos en función de optimar su posicionamiento en la competencia internacional.

Posteriormente, en los noventa se avanzó hacia un sistema económico desregulado, en particular en lo referido al mundo financiero, cuyos activos se multiplican a gran velocidad, con un respaldo cada vez menor en la economía real. Este sistema priorizó la liberalización comercial, sin tomar en cuenta los problemas específicos de competitividad, equilibrio externo y deterioro ambiental que afectaban a las economías en desarrollo (CEPAL, 2000).

Según Svampa y Viale (2014), más allá de ciertas rupturas en Argentina luego de la crisis de 2001, en la década de los 2000 se mantuvieron las bases normativas y jurídicas que 
sostienen el actual modelo de desarrollo. De esta forma, y sumado los altos precios de la materia prima, se profundizó un modelo de desarrollo basado en actividades primarioextractivas, lo que estos autores han denominado el nuevo "Consenso de los Commodities" debido a que este camino tomado para alcanzar el desarrollo ha sido adoptado tanto por los gobiernos progresistas como por aquellos más conservadores de la región.

Este modelo sintetiza la convivencia de altos índices de crecimiento económico, extracción de recursos naturales, crecimiento de la desigualdad y graves conflictos socioambientales en nuestro continente (Gudynas, 2012; Dos Santos, 2002).

Por otro lado, la comunidad internacional ha planteado la configuración de una amplia agenda social y ambiental, sin embargo, la misma no ha sido acompañada de su contrapartida en términos de flujos de recursos internacionales necesarios para apoyarla, de una institucionalidad mundial que le sea propicia, ni tampoco del compromiso de los países centrales de traducirla en políticas nacionales consistentes (CEPAL, 2000).

Para el citado organismo, la dificultad central radica en la economía política, el conjunto de intereses y alianzas que predominan y que definen las reglas del juego, tanto en el plano internacional como en el interno. En este sentido, diversos actores, tanto públicos como privados, tienen interés en proteger sus inversiones y la distribución presente de rentabilidades, lo que se refleja en la contradicción existente entre las declaraciones de las instituciones internacionales y las reglas que gobiernan la dinámica económica (CEPAL, 2016).

Esto mismo se ve reflejado en los debates sobre sostenibilidad y desarrollo sostenible donde prevalece la visión economicista clásica que considera a la economía como el sistema prioritario y relega la naturaleza al papel de proveedor de recursos naturales y sumideros de desechos de la actividad humana (García, 2006).

Por este motivo, Raúl Prada (2011) aborda el tema con mayor radicalidad, y sostiene que es necesario quebrar los monopolios de los países imperialistas del centro del sistema mundo capitalista. Entre estos quiebres de los monopolios se encuentra el monopolio del acceso de las riquezas naturales del planeta, el monopolio financiero, el tecnológico, el de los medios de información y de comunicación, fuera del monopolio de las armas de destrucción masiva. Esta lucha antimonopólica por parte de los países del sur no solo debe generar un mundo multipolar sino también debe provocar a una revolución cultural a escala mundial, que no solo signifique la ruptura y el desplazamiento epistemológico sino también una recodificación y revalorización múltiples de las conductas, los comportamientos, las prácticas, los imaginarios, los cuerpos, en un contexto de procesos y acontecimientos que logren transformaciones institucionales, económicas, políticas y culturales. El desarrollo económico debe enfocarse hacia el fortalecimiento del mercado interno, es decir, la relación de las 
economías locales y regionales con la economía mundo capitalista. También debe optar por la soberanía alimentaria y por la satisfacción de las necesidades básicas de la población, visibilizando la relación de los derechos fundamentales, construyendo un modelo productivo alternativo, pensado también en otras relaciones no-capitalistas y otros sujetos que respondan a otras valoraciones múltiples del trabajo, retomando simbolismos interpretativos culturales que fortalezcan las solidaridades y las cohesiones.

\section{Las externalidades del desarrollo hegemónico}

Insostenibilidad equivale a extinción. Con estas palabras Jonathon Porrit (2003) invita a la reflexión respecto a la necesidad de no pensar en la sostenibilidad como una opción sino como un imperativo innegociable. En este sentido, las cuestiones ambientales se han vuelto cada vez más centrales para el desarrollo, como así también el desarrollo se ha convertido en una preocupación central de la ecología política (Gómez, 2015).

Si las tendencias actuales persisten, la humanidad terminará por modificar de forma dramática los ecosistemas naturales (Lubchenco, 1998). Nuestro planeta se ha alterado en los últimos dos siglos con una intensidad sin precedentes en la historia de la humanidad. A través de las actividades que realiza el ser humano se provoca la transformación de la tierra, el mar, los ciclos biogeoquímicos, y se agregan o eliminan especies genéticamente diferentes (García, 2006).

Esto ha provocado alteraciones en las temperaturas, en el nivel de precipitaciones, en los caudales de ríos y disponibilidad de agua. También es la causa de la profundización del retroceso de los glaciares, el aumento del nivel del mar, el deterioro de las zonas costeras, la extinción masiva de especies a nivel global, y disfuncionalidades ecológicas a escala planetaria, entre otros efectos negativos de la crisis ambiental (Gudynas, 2015; IPCC, 2013).

En la misma línea, el informe "Cambio Climático 2013" realizado por el Grupo Intergubernamental de expertos sobre el Cambio Climático de la ONU (IPCC, 2013) resalta esta urgencia, y detalla los cambios en la atmósfera, los océanos, la criósfera, y el nivel del mar que se desarrollaron durante las últimas décadas.

A su vez, la Comisión Económica para América Latina (CEPAL) destaca el daño en el ambiente que afecta recursos comunes, como lo son el océano, la atmósfera, la biodiversidad y las capas polares, afirmando que el mismo es producto del crecimiento económico. Así, de forma contundente, afirma que "la humanidad se encuentra ante un punto de no retorno" (CEPAL, 2016, pp. 53). 
A esta realidad se ha llegado, como afirma Alvater (2011), debido al desinterés por reconocer los límites naturales de almacenamiento de los recursos energéticos y minerales, de la extracción de los recursos, de la sumisión de residuos, como así también por no respetar los tiempos y los ciclos de la naturaleza.

En este sentido, el primer informe del Club de Roma sobre los límites naturales al crecimiento realizado en la década del 70 , predijo la superación de estos límites para la segunda década del siglo $\mathrm{XXI}$, si continuaban las tendencias entonces existentes. Sin embargo, la revisión de este informe publicado en la década del 2000 confirmó la superación de estos límites una década antes de lo predicho (García, 2006).

Así, el futuro de las sociedades industriales está lejos de estar asegurado (Riechman, 2006), ya que, como afirma García (2006), la superación de los límites naturales al crecimiento significa, entre otras cosas, el fin de la era del desarrollo, y con ello, las teorías que postulan el indefinido crecimiento del mismo.

Por este motivo, es indispensable acercarse a la propuesta de Hinkelammert y Mora Jiménez (2014), quienes sostienen que lo que resulta una externalidad para el sistema es, a la vez, lo esencial para la vida humana. La falta de acceso a bienes elementales, el desempleo y la destrucción de la naturaleza no pueden ser considerados como simples efectos externos. De aquí que el sentido de progreso o prosperidad sostenido por la cultura occidental debe ser deconstruido (Jackson, 2009), destacándose el rol de los teóricos del desarrollo en esta tarea.

\section{La crisis no es ambiental}

Así como para el neoliberalismo, todo intento en dirección opuesta al mercado es errónea e inviable (Alvater, 2011), no debería ser que para gran parte del arco heterodoxo, todo intento en dirección opuesta al productivismo también sea errónea e inviable.

Según Tim Jackson (2009), la visión que prevalece hoy en día concibe a la prosperidad como la continua expansión económica, y a la satisfacción que genera el consumo de bienes materiales, que no está atado solamente a las necesidades fisiológicas, sino que además es promovido por una cultura consumista que genera una competencia por el estatus que daña psicológica y socialmente a las personas.

Alberto Acosta y Ulrich Brand (2017), a su vez, sostienen que paulatinamente, comenzó a expandirse por el Sur global un modo de vida que basa su arraigo en la sociedad a través del acceso al consumo de bienes de estatus como autos, casas unifamiliares y productos industriales, siendo un atractivo para la clase media de la región. A este modo de vida lo definen como modo de vida imperial, dado que, mediante medios políticos, jurídicos y/o 
violentos, presupone el acceso ilimitado a recursos naturales, espacio territorial, fuerza laboral, y sumideros de contaminación.

De esta manera, el motor de acción en la vida de los individuos es el apuntalamiento del estatus. Así, la idea de que los pueblos pobres podrán algún día disfrutar de las formas de vida de los actuales países ricos fue utilizada para movilizar a los pueblos de la periferia y llevarlos a aceptar enormes sacrificios, como la destrucción de culturas arcaicas y el medio físico (Gudynas, 2011) reforzando el carácter insostenible del modelo de desarrollo.

De esta forma, el imaginario de éxito y felicidad planteado desde el Norte global para la humanidad requiere, entre otras prácticas insostenibles, de la perforación del fondo del mar y la explotación de arenas con alquitrán para extraer petróleo, la infiltración de químicos en capas geológicas para liberar gas natural, la excavación de cráteres a gran escala para obtener el $0,1 \%$ del cobre que contiene el suelo, el acaparamiento de tierras agrícolas para la especulación financiera y la producción de agrocombustibles (Lang, 2011).

Por este motivo, no es la naturaleza en si lo que está en crisis, sino lo que está en crisis son las formas sociales, es decir, como las personas se apropian de los elementos de la naturaleza. En cómo están organizadas las sociedades, sus procesos de producción y de consumo radica la causa del problema (Acosta y Brand, 2017).

Sin embargo, existen otras visiones que afirman que la prosperidad tiene una dimensión material pero también tiene una dimensión psicológica, social, intra e intergeneracional. Estas visiones cercanas a Aristóteles, y Amartya Sen, rescatan la necesidad de "florecer" como seres humanos, es decir, de lograr el desarrollo de las potencialidades humanas. Aquí los elementos más importantes son la alimentación, la vivienda, el acceso a los bienes materiales elementales, la salud, la esperanza de vida, el tipo de trabajos, y la habilidad de participar libremente de la vida social, entre otros (Acosta y Martínez, 2014; Jackson, 2009).

De esta manera, afirma Sen (2010), la riqueza no es algo que valoremos por sí mismo ni es un buen indicador de la clase de vidas que podemos vivir con base en nuestra riqueza. Al juzgar las ventajas que unas personas tienen en comparación con otras, tenemos que mirar a las capacidades generales de las cuales unas y otras consiguen disfrutar. Las personas pueden tener muy diferentes oportunidades de convertir el ingreso y otros bienes primarios en características de la buena vida. Así, la relación entre recursos y pobreza es tanto variable cuanto dependiente de las características de las respectivas personas y del ambiente natural y social en el cual viven.

Al plantear un cambio esencial en el foco de atención de los medios de vida a las oportunidades reales de la persona, se orienta a un giro radical en los enfoques evaluativos regulares ampliamente utilizados en economía y estudios sociales. 
Además, nuestra disposición mental, nuestras expectativas y nuestros deseos tienden a ajustarse a las circunstancias, a lo que resulta factible (Sen, 2010). Esta idea es fundamental, ya que la capacidad del planeta de suministrar servicios está decreciendo y la humanidad avanza hacia un futuro con dos caminos posibles, o bien de una contienda global por el acaparamiento de los recursos en declive, o de un esfuerzo heroico y cooperativo encaminado a una conservación radical, y en transición a hacia un régimen energético post combustible fósil (García, 2006).

Así, y dado que el futuro cercano será uno de escasez y austeridad, se debe asegurar la calidad de vida dentro de opciones mucho más estrechas en su apropiación (Gudynas, 2011).

En esta línea Ha-Joon Chang (2015), afirma que los países desarrollados deben reducir sus niveles de consumo, sin que esto signifique reducir su bienestar. Su propuesta se basa en cambios culturales que promuevan un consumo diferente, basado en el consumo colectivo y no individual, y así reducir el nivel de consumo agregado.

A su vez, en el espacio comunitario se recrean los siguientes principios: reciprocidad, propiedad colectiva, relación y convivencia con la naturaleza, responsabilidad social, consensos, etc. (Simbaña, 2011). Esto lo convierte en el espacio de interacción fundamental para pensar en nuevos paradigmas de desarrollo.

Por último, no es menor destacar que la Comisión Económica para América Latina y el Caribe (CEPAL) sostiene que

el desarrollo también debe tener como metas construir un clima social y humano de mayor seguridad y confianza mutua; consolidar un orden político democrático con más participación de las personas en la gestión y las decisiones públicas; difundir el bienestar hacia quienes tienen menos acceso a los beneficios de la modernidad; tomar forma en proyectos colectivos en que los ciudadanos adquieran un mayor sentido de compromiso y pertenencia respecto de la sociedad en que viven; y buscar la protección y mejoramiento del hábitat natural para quienes lo habitan hoy y quienes lo harán en el futuro (CEPAL, 2000, p. 51).

De esta forma, la salida -o disminución- del individualismo y la competencia, ejes principales del capitalismo, son requisitos indispensables, no solo para pensadores radicalizados sino también para organismos de Naciones Unidas como la CEPAL.

En este sentido, la economía solidaria es una crítica radical al sistema capitalista que se realiza desde la práctica. La propiedad y gestión colectiva e igualitaria es una superación al actual modelo de supervivencia del más apto.

Sin embargo, la negación del consumo y el crecimiento cero pueden no ser suficientes para generar un mundo verde si al mismo tiempo no se transforman las instituciones sociales que regulan la acumulación de capital (Alvater, 2011). De esta forma, el cooperativismo debe 
ser tomado como una posible alternativa que promueve estas nuevas formas de entender el desarrollo.

\section{El cooperativismo es parte de la alternativa}

Desde los orígenes de la humanidad ha existido el trabajo colectivo. La especie humana surge producto del trabajo de forma colectiva y cooperativa en sociedades donde no existía la propiedad privada. Luego, aun hallando otras formas predominantes de organizar el trabajo, como la esclavitud, el feudalismo y el capitalismo, el cooperativismo ha logrado persistir a lo largo de los años. Las cooperativas modernas surgen a finales del siglo XVIII a partir de la revolución industrial, a partir de la necesidad de alivianar las malas condiciones de vida de la clase obrera en Inglaterra (Cruz Reyes y Piñeiro Harnecker, 2012).

Según la Alianza Cooperativa Internacional $(\mathrm{ACl})$, una cooperativa es una asociación autónoma de personas que se han unido en forma voluntaria para satisfacer en común sus necesidades y aspiraciones económicas, sociales y culturales, mediante una empresa de propiedad conjunta y administración democrática.

Como desarrollan Juan Cruz Reyes y Camila Piñeiro Harnecker (2012), una cooperativa es una asociación y una empresa a la vez, donde lo asociativo y social es lo que guía el funcionamiento empresarial. Dado que cada cooperativista tiene el mismo poder de toma de decisiones independientemente del capital que hayan aportado, estos autores definen a la cooperativa como una empresa de personas y no de capitales. A su vez, se sostiene que las cooperativas que son exitosas a lo largo del tiempo son aquellas que cuentan con ciertos principios organizativos, que la $\mathrm{ACl}$ define como: la membrecía voluntaria y abierta, la gestión democrática por parte de los asociados, la participación económica de los asociados, la autonomía e independencia, la educación y formación de los asociados, la cooperación entre cooperativas, y el interés o compromiso por la comunidad. En este sentido, se espera que el cooperativismo responda no solo a los intereses de los asociados sino también al de la comunidad, preservando sus condiciones del hábitat, y promoviendo un camino de desarrollo verdaderamente sostenible para la comunidad.

En este sentido, Amartya Sen (2003) sostiene que lograr un uso compartido, aun de forma incompleta, puede ser un recurso muy valioso para preservar las condiciones ambientales.

A su vez, la autogestión constituye un acto colectivo que produce resultados en las organizaciones y en el desarrollo de los individuos que forman parte (ACIJ, 2016). La autogestión permite resolver con nuestras manos nuestras propias necesidades, a partir de 
nuestro trabajo, esfuerzo y creatividad, gestionando los recursos de forma democrática y en el interés de todos. En ella se involucran prácticas, sentidos e imaginarios sociales que se contraponen a la concepción individualista predominante en la sociedad (Cruz Reyes y Piñeiro Harnecker, 2012).

En esta línea, Humberto Miranda Lorenzo (2012) sostiene que la autogestión va indisociablemente unida a una mejora cualitativa de las condiciones de vida. La cooperación, la ayuda mutua, la autoadministración de los productores asociados no responden a una pulsión idealista sino a una necesidad y deseo de aumentar los goces colectivos y reducir los sufrimientos. La autogestión es un concepto que abarca una actitud y actuación ante la vida, no solo dentro de los límites del proceso productivo. En este sentido, se propone la autogestión como un proceso de combinación de factores económicos, políticos, psicológicos y afectivos.

Por este motivo, es importante que las personas que integran cooperativas logren interiorizar que mediante la cooperación pueden resolver sus necesidades comunes no resueltas no solo en el ámbito material y de forma coyuntural, sino que tomen conciencia sobre la necesidad de unirse como un modo de vida que valora dimensiones de la naturaleza humana que no podrá desarrollarse en otras formas de organización del trabajo. Esto implica que las personas que integran la cooperativa no sean simplemente personas que buscan resolver una necesidad individual, sino que sean realmente cooperativistas, principio fundamental para el éxito de una cooperativa (Cruz Reyes y Piñeiro Harnecker, 2012).

Por último, se señala que el cooperativismo no implica solamente una mayor difusión de principios y valores éticos como la solidaridad, equidad, justicia, etc., sino que ha colaborado en términos materiales en millones de empleos a nivel global, la prestación de servicios y producción hasta las capas de menor poder adquisitivo, y la elevación del nivel de vida de millones de personas. Se estima que en la actualidad, la mitad de la población mundial está asociada en alguna de las mil millones de cooperativas que existen en el mundo (Rivera Rodríguez, et. al., 2012).

En conclusión, con un orden económico no soportable e insostenible, y ante una crisis global inédita, el cooperativismo presente en todas las ramas del quehacer humano, se erige como una posible alternativa al desarrollo (Ibid, 2012).

\section{Cooperativismo en la Ciudad de Buenos Aires: La autogestión del hábitat es posible}

El hábitat popular se vio fuertemente impactado durante la década del 90 debido a un proceso de urbanización orientado a la acumulación privada de capital. Reflejado en la 
desinversión pública en producción de vivienda e infraestructura, este proceso tuvo como consecuencia una grave emergencia socio-habitacional. De esta forma, y en el marco de una exclusión del mercado de trabajo de un amplio sector de la sociedad, quienes se vieron afectados fueron obligados a buscar diversas formas de supervivencia, siendo una de ellas el proceso de organización y movilización que dio lugar al surgimiento a nuevas estrategias habitacionales en la ciudad (Raspall, S.F.; Zapata, 2013).

De esta forma se destacó, hacia fines de la década del 90, el trabajo de algunas organizaciones sociales en función de defender su derecho a la ciudad, como es el caso de la asamblea de desalojados de La Boca y el comedor Los Pibes, el Movimiento de Ocupantes e Inquilinos (MOI), y delegados de la Ex Autopista 3. Estas organizaciones lograron integrar una mesa de trabajo junto a la Comisión de Vivienda de la Legislatura porteña y funcionarios del poder ejecutivo de la Comisión Municipal de Vivienda (CMV), donde propusieron un proyecto de ley de autogestión, y discutieron el contenido que luego iba a conformar al Plan de Autogestión de la Vivienda (PAV) en el marco de la ley 341 (Raspall, S.F). Esto permite pensar en el PAV como un programa nacido al calor de las luchas populares (Raspall, S.F.; Thomasz, 2008), como respuesta a una deficiencia del capitalismo para garantizar el derecho a la ciudad a toda la población (Zapata, 2013).

Considerada una experiencia pionera de institucionalidad que habilita la producción autogestionaria del hábitat en la Argentina, en diciembre del año 2000 es sancionada en la Ciudad de Buenos Aires la ley 341. Esta ley tiene como objetivo otorgar créditos con garantía hipotecaria a familias de escasos recursos incorporadas en organizaciones colectivas verificables, para que de manera autogestionaria compren un terreno en la ciudad, construyan sus viviendas, y contraten un equipo técnico de profesionales que los asesore en este proceso. Estas organizaciones sin fines de lucro, entre las que podemos nombrar cooperativas, mutuales, asociaciones civiles, entre otras, tienen como horizonte, más allá del acceso a la vivienda, el desarrollo integral del hábitat (ACIJ, 2016).

EI PAV, sancionado por la Ley $\mathrm{N}^{\circ} 341$, fue implementado y ejecutado por la Unidad de Gestión del PAV dependiente de la Gerencia de Créditos de la ex Comisión Municipal de la Vivienda (CMV), actualmente el Instituto de la Vivienda de la Ciudad de Buenos Aires (IVC). Su objetivo fue el de instrumentar políticas de acceso a la vivienda para uso exclusivo y permanente de hogares de bajos recursos, en situación de crisis habitacional. El programa consistió en el otorgamiento de subsidios o créditos de garantía hipotecaria a destinatarios individuales o incorporados en organizaciones colectivas verificables, con el fin de financiar la compra de terrenos urbanos, la contratación de equipos técnicos interdisciplinarios (ETI) para asesorar a la cooperativa en todo el proceso de obra, y la construcción, ampliación y/o refacción de las viviendas, ya sea de forma parcial o total. La población objetivo se 
determinaba en función de los ingresos mensuales de los posibles beneficiarios, los cuales no debían superar la línea de la pobreza, y de su patrimonio personal, ya que no podían ser propietarios de otra vivienda en la ciudad. A su vez, se estableció que la cuota tope para devolver el crédito hipotecario no podía superar el $20 \%$ del ingreso del hogar, siendo el resto de la cuota subsidiada, ya que la cancelación del crédito se efectuaría en 360 cuotas mensuales, iguales y consecutivas (Zapata, 2013).

Como resultado, el Programa de Autogestión de la Vivienda (PAV) tenía, a fines de 2015, 7688 familias beneficiarias en un total de 405 organizaciones inscriptas. Entre ellas, 110 organizaciones han logrado la compra de terrenos, 31 organizaciones han finalizado obras y 8 de ellas han escriturado. Los terrenos comprados por estas organizaciones se encuentran en diversas comunas, siendo la centralidad urbana de las mismas una de las características más destacables (ACIJ, 2016; Zapata, 2013).

Así, se destaca la construcción del Barrio Monteagudo realizado por el Movimiento Territorial de Liberación (MTL) en Parque Patricios, que cuenta con 326 viviendas, un jardín maternal, una radio, un salón de usos múltiples, una plaza, nueve patios internos y diez locales comerciales. Este barrio es el conjunto de mayor envergadura construido en el marco del PAV, en un plazo de 36 meses de trabajo. También se señala el trabajo de la cooperativa Los Pibes, que construyó en la Boca un complejo de 33 viviendas de 65 metros cuadrados cada una, y el Paseo de La Economía Popular Martín "Oso" Cisneros, donde todos los sábados se realiza una feria popular en la que cooperativas y productores ofrecen sus productos. Por último, se destaca el programa de la cooperativa MOI-CTA, ejemplo de proyecto educativo y de salud, que surgió por iniciativa de los propios integrantes de la cooperativa; el que cuenta con un jardín maternal, un área recreativa, dos bibliotecas populares, dos bachilleratos populares, y un área de investigación y capacitación (ACIJ, 2016).

A partir del estudio de estas experiencias y sus resultados, es que se puede pensar de forma auspiciosa en el cooperativismo como forma de organizar el trabajo humano, que permita avanzar en la construcción de modelos de desarrollo verdaderamente sostenibles. Sin embargo, la revisión bibliográfica sobre esta experiencia y el incipiente trabajo de campo volcado en este texto no permite afirmar determinadas cuestiones importantes que serán fruto de próximas investigaciones.

Entre estos interrogantes se podrían mencionar, por ejemplo, si se constata el cumplimiento de los principios cooperativos, principalmente el que hace referencia al compromiso para con la comunidad, lo que implica analizar el impacto sobre el hábitat de las actividades que realizan las cooperativas. También sería importante profundizar si los cooperativistas han logrado superar los límites del proceso estrictamente productivo, y han avanzado en la concepción del cooperativismo no solo como una herramienta para resolver el 
problema habitacional sino para pensar bastas dimensiones de la vida, como el trabajo, el consumo, el ocio, etc. Estos avances permitirían el análisis respecto a las características de las formas de consumo que se dan en los cooperativistas, a fin de evaluar si el consumo colectivo permite, en términos cualitativos y cuantitativos, reducir el consumo material y aumentar el nivel de bienestar de la comunidad, dimensión importante para enfrentar la crisis ambiental, y para pensar en alternativas viables al desarrollo.

\section{Reflexiones finales}

A modo de conclusión, lo que resulta una externalidad para el sistema es, a la vez, lo esencial para la vida. La destrucción de la naturaleza no puede ser considerada como un simple efecto externo de nuestras actividades económicas. En este sentido, no hay desarrollo si el mismo es alcanzado mediante prácticas que no permiten, a su vez, garantizar las condiciones para la reproducción de las mismas, aun si estas permiten momentáneamente el crecimiento en el nivel de consumo de algunas sociedades.

El sostenimiento de las condiciones ambientales donde se va a desarrollar la actividad económica (extracción, producción, comercialización, consumo y excreción) debe ser un elemento central en las teorías del desarrollo, como así también discutir el objetivo final al cual va a tributar la receta propuesta, aunque la misma se considere microeconómica o sectorial.

Aunque se ignore el tema, el soporte físico de la producción social es el ambiente, y el mismo no soporta niveles de extracción, producción y generación, tanto de gases como de residuos mayores a los existentes actualmente. Entonces, o bien ignoramos el tema y nuestras propuestas no pueden ser llevadas adelante, o bien aceptamos la condición excluyente del modelo propuesto, ya que este implicaría que nuestro mayor nivel de consumo dependa del subconsumo relativo de otras sociedades pobres o de la profundización de la superación de los límites naturales a la extracción de naturaleza, emisión de gases y generación de residuos que hoy nos lleva al peligro de extinción como especie.

Si la era del desarrollo está destinada a desaparecer, junto a sus teorías, perdurar en un planeta habitable, utilizando el título del trabajo de Jorge Riechman, debe ser no solo un deseo sino una obligación para el trabajo de un teórico del desarrollo.

No es la naturaleza en sí lo que está en crisis sino las formas sociales, es decir, cómo las personas se apropian de los elementos de la naturaleza y llevan adelante los procesos de producción y consumo.

La modernidad expresa una manera de ser y entender el mundo que separa nítidamente la sociedad de la naturaleza y que la subordina bajo una jerarquía que permite manipularla y destruirla. Esta mirada debe ser superada, ya que incluyendo a las sociedades humanas 
dentro de la Naturaleza, la idea de "desarrollarnos" a costa de la depredación del ambiente se vuelve un absurdo, ya que el desarrollo necesariamente implica una progresión en las condiciones de la vida, y no una amenaza para la misma.

El devenir de la crisis multifacética e interrelacionada por la que atraviesa la humanidad nos obliga a redefinir lo que entendemos como progreso y como desarrollo, abandonando la idea de que el mismo se relaciona con la acumulación de riqueza y el acceso al (hiper) consumo.

Esta concepción del desarrollo explica las constantes fallas por parte de la comunidad internacional al momento de cumplir con sus agendas propuestas, ya que terminan primando intereses económicos.

Por este motivo, si se busca un cambio de paradigma que permita pensar en el desarrollo de actividades económicas que sean verdaderamente sostenibles en el tiempo, la lucha antimonopólico por parte de los países del sur no solo debe generar un mundo multipolar sino también debe provocar una revolución cultural a escala mundial, que no solo signifique la ruptura y el desplazamiento epistemológico sino también una recodificación y revalorización múltiples de las conductas, los comportamientos, las prácticas, los imaginarios, los cuerpos, en un contexto de procesos y acontecimientos que logren transformaciones institucionales, económicas, políticas y culturales. Sin embargo, la negación del consumo y el crecimiento cero pueden no ser suficientes para generar un mundo verde si al mismo tiempo no se transforman las instituciones sociales que regulan la acumulación de capital.

En este sentido, el cooperativismo y la autogestión permiten resolver con nuestras manos nuestras propias necesidades, a partir de nuestro trabajo, esfuerzo y creatividad, gestionando los recursos de forma democrática y en el interés de todos. Así, se involucran prácticas, sentidos e imaginarios sociales que se contraponen a la concepción individualista predominante en la sociedad, mejorando nuestro bienestar de forma colectiva, promoviendo la solidaridad y la mayor cohesión social.

De esta forma, contribuciones de Amartya Sen pueden ser tomadas en cuenta para pensar en alternativas al desarrollo. Si consideramos que el grado de desarrollo de un país está determinado por la capacidad de sus ciudadanos de participar libremente de la vida social, restando importancia al nivel de riqueza, el desarrollo deja de ser una meta que excluye a millones de personas para involucrar a toda la sociedad en su conjunto.

En síntesis, el estudio preliminar ha permitido visualizar que es posible materializar una forma de producción alternativa y eficiente, basada en relaciones no-capitalistas y sujetos que responden a otras valoraciones múltiples del trabajo, retomando, así, simbolismos interpretativos culturales que fortalecen las solidaridades y las cohesiones. Realizado este primer paso, resta profundizar la investigación para responder interrogantes pendientes. 


\section{Referencias bibliográficas}

ACIJ (2016). ¿Por qué y para qué impulsar políticas públicas para la producción autogestionaria del hábitat? Buenos Aires, Asociación Civil por la Igualdad y la Justicia, colección es nuestra la ciudad $-\mathrm{n}^{\circ} 1$.

Acosta, A. y Brand, U. (2017). Decrecimiento y Postextractivismo. Buenos Aires: Tinta Limón y Fundación Rosa Luxemburgo.

Acosta, A. y Martínez, E. (2014). Desarrollo, postcrecimiento y buen vivir. Debates e interrogantes. Quito: Ediciones Abya-Yala.

Alvater, E. (2011). Los límites del capitalismo, acumulación crecimiento y huella ecológica. Buenos Aires: Mardulce.

CEPAL (2000). Equidad, desarrollo y ciudadanía. Santiago de Chile: Publicación de las Naciones Unidas.

CEPAL (2016). Horizontes 2030. La Igualdad en el centro del Desarrollo Sostenible. Santiago de Chile: Publicación de las Naciones Unidas.

Chang, H. (2015). Economía para el 99\% de la población. Buenos Aires: Debate.

Cruz Reyes, J. y Piñeiro Harnecker, C. (2012). ¿Qué es una cooperativa? En Piñeiro Harnecker, Camila (Comp.). Cooperativas y Socialismo: Una mirada desde Cuba. La Habana: Editorial Caminos.

Dos Santos, T. (2002). La teoría de la dependencia. Balance y perspectivas. Madrid: Plaza Janés.

García, E. (2006). El cambio social más allá de los límites al crecimiento. En Riechmann J. (comp). Perdurar en un planeta habitable. Ciencia, tecnología y sostenibilidad. Barcelona: Icaria editorial.

Gudynas, E. (2011). Debates sobre el desarrollo y sus alternativas en América Latina: Una breve guía heterodoxa. En Lang, M. y Mokrani, D. (comp). Más allá del desarrollo. Quito: Fundación Rosa Luxemburgo - Ediciones Abya Yala.

Gudynas, E. (2012). Estado compensador y nuevos extractivismos. Las ambivalencias del progresismo sudamericano en Nueva Sociedad 237.

Gudynas, E. (2015). Derechos de la Naturaleza. Buenos Aires: Tinta Limón.

Hinkelammert, F. y Mora Jiménez, H. (2014). Hacia una economía para la vida. La Habana: Editorial Caminos - Editorial Filosofi@.cu.

Hirsch, J. (1999). La globalización del capital y la transformación de los sistemas de estado: del estado nacional soberano al estado nacional de competencia. Cuadernos del Sur 28. 
Divulgatio. Perfiles académicos de posgrado, Vol. 2, Número 6, 2018, 103-120

IPCC (2013). Cambio Climático 2013. Recuperado (02-07-2017) $<$ http://www.ipcc.ch/pdf/assessmentreport/ar5/wg1/WG1AR5_SummaryVolume_FINAL_SPANISH.pdf> Jackson, T. (2009). Prosperity without growth. Economics for a finite planet. Londres: Earthscan.

Lang, M. (2011). Crisis civilizatoria y desafíos para las izquierdas. En Lang, M. y Mokrani, D. (comp). Más allá del desarrollo. Quito: Fundación Rosa Luxemburgo - Ediciones Abya Yala.

Lubchenco, J. (1998). Entering the century of environment: a new social contract for science. Science 279,5350 .

Gómez, M. (2015). Una aproximación a las contribuciones de Arturo Escobar a la ecología política. Revista Ecología Política 50, 100-105.

Miranda Lorenzo, H. (2012). Cooperativismo y autogestión en las visiones de Marx, Engels y Lenin. En Piñeiro Harnecker, Camila (Comp.). Cooperativas y Socialismo: Una mirada desde Cuba. La Habana: Editorial Caminos.

Olive, L. (2003). La democratización de la ciencia desde la perspectiva de la ética. En López Cerezo, J. (comp.). La democratización de la ciencia. Donostia: Erein.

ONU-Habitat (S.F.). El cambio climático. Rio de Janerio. Recuperado (02-07-2017):

http://es.unhabitat.org/temas-urbanos/cambio-climatico/

Porritt, J. (2003). Actuar con prudencia: ciencia y medio ambiente. Barcelona: Blume.

Prada, R. (2011). Horizontes del Estado Plurinacional. En Lang, M. y Mokrani, D. (comp). Más allá del desarrollo. Quito: Fundación Rosa Luxemburgo - Ediciones Abya Yala.

Raspall, T. (S.F.). Características del cooperativismo de vivienda en la Ciudad de Buenos Aires en el período 2001-2008. Buenos Aires: Centro de Estudios de Sociología del Trabajo, Facultad de Ciencias Económicas, Universidad de Buenos Aires. Recuperado (28-2-2017): http://www.econ.uba.ar/cesot/docs/Documento\%2070.pdf

Riechmann, J. (2006). Introducción: perdurar en un planeta habitable. En Riechmann J. (comp). Perdurar en un planeta habitable. Ciencia, tecnología y sostenibilidad. Barcelona: Icaria editorial.

Rivera Rodriguez, C; Labrador Machin O. y Aleman, J. (2012). Retos del cooperativismo como alternativa al desarrollo ante la crisis global. Su papel en el modelo económico cubano. En Piñeiro Harnecker, C. (Comp.). Cooperativas y Socialismo: Una mirada desde Cuba. La Habana: Editorial Caminos.

Sen, A. (2003). ¿Qué impacto puede tener la ética? Seminario Internacional "Ética y Desarrollo". Banco Interamericano de Desarrollo.

Sen, A. (2010). La idea de justicia. México D.F: Taurus.

Simbaña, F. (2011). El sumak kawsay como proyecto político. En Lang, M. y Mokrani, D. 
(comp). Más allá del desarrollo. Quito: Fundación Rosa Luxemburgo - Ediciones Abya Yala. Svampa, M. y Viale, E. (2014). Mal desarrollo. Buenos Aires: Editorial Katz.

Thomasz, A. (2008). Historia y etnografía de una normativa polémica: la Ley 341 y el Programa de Autogestión para la Vivienda. Cuadernos de Antropología Social 28, Filo, UBA. Recuperado (28-2-2017): http://www.scielo.org.ar/scielo.php?script=sci arttext\&pid=S1850-

\section{$\underline{275 X 2008000200007}$}

Vernengo, M. (2006). Technology, finance, and dependency: Latin American radical political economy in retrospect. Salt Lake City, Review of Radical Political Economics.

Zapata, M. (2013). El Programa de autogestión para la vivienda: El ciclo de vida de una política habitacional habilitante a la participación social y del derecho al hábitat y a la ciudad. Buenos Aires: Instituto de Investigaciones Gino Germani, Facultad de Ciencias Sociales, Universidad de Buenos Aires. Recuperado

http://biblioteca.clacso.edu.ar/Argentina/iigg-uba/20130619030459/dji36.pdf 